\title{
REDES, SOCIEDADE INFORMACIONAL E INTERNET: OS USOS POLÍTICOS DO ON-LINE NA CONTEMPORANEIDADE A PARTIR DA MASSIFICAÇÃO DE PÓS-VERDADES E DE FAKE NEWS
}

Networks, information society and the Internet: the political uses of online in contemporary times from the standardization of post-truths and fake news

\author{
Júlio Marinho Ferreira'
}

\begin{abstract}
Resumo
Este artigo propõe uma discussão a partir do conceito de redes, que evoca toda uma literatura filosófica, que passaria de Descartes chegando ao século XX com o conceito de sociedade em rede, além de seus usos sociológicos. Dessa forma, através de uma análise sociológica que versa sobre a relação da informação com a sociedade e com a tecnologia informacional, através da ascensão de uma rede internacional comunicacional (a Internet), primeiro utilizada como ferramenta militar, sendo em seguida uma produtora de conhecimento, para depois se tornar uma geradora de interações sociais variadas, fez aparecer a questão de uma existência, de indivíduos, no plano do digital/virtual, com a possibilidade de criação de perfis e de outras ferramentas interativas. Ademais, com o modelo chamado de sociedade informacional, estabelecida através da forte relação entre informação e Internet, nos últimos vinte anos (Web 1.0, 2.0, 3.0 e 4.0) o mundo digital/virtual do on-line, com suas dualidades e paradoxos entre realidade e virtualidade promoveu o uso de imagens on-line, que poderiam ser usadas e manipuladas. E na contemporaneidade, com uma latente massificação do acesso às redes sociais digitais/virtuais e a ascensão da chamada pós-verdade, com os conteúdos fake news e perfis falsos, surge a questão do uso político das mesmas, e como isso afetaria as noções sociais de verdade, de ciência e de democracia.
\end{abstract}

Palavras-chave: Sociologia, tecnologia, virtual, digital, web

\begin{abstract}
This article proposes a discussion based on the concept of networks, which evokes a whole philosophical literature that would go from Descartes to the twentieth century with the concept of network society, in addition to its sociological uses. Thus, through a sociological analysis that deals with the relationship of information with society and information technology, through the rise of an international communication network (the Internet), first used as a military tool, and then a producer of knowledge to later become a generator of varied social interactions, raised the question of an existence of individuals, in the digital / virtual plane, with the possibility of creating profiles and other interactive tools. Moreover, with the so-called information society model, established through the strong relationship between information and the Internet, in the last twenty years (Web 1.0, 2.0, 3.0 and 4.0)
\end{abstract}

1Doutorando em Sociologia pela Universidade Federal de Pelotas, bolsista Capes/CNPq. Email: juliomarferre@hotmail.com. 
Redes, sociedade informacional e internet: os usos políticos do on-line na contemporaneidade a partir da massificação de pós-verdade e fake news | Júlio Marinho Ferreira

the digital / virtual world of online, with its dualities and paradoxes between reality and virtuality promoted the use of online images that could be used and manipulated. And in contemporary times, with a latent standardization of access to digital / virtual social networks and the rise of the so-called post-truth, with fake news content and fake profiles, the question of their political use arises, and how would it affect social notions? of truth, science and democracy.

Keywords: Sociology, technology, virtual, digital, web.

\section{Introdução}

A sociedade do século XXI, tendo absorvido a tecnologia, pode-se dizer, em quase todas as suas esferas, classes e instituições, alterou a forma como os individuos interagem entre si, e essa nova forma acabou sendo apropriada pelo mercado como tendência unilateral e impositiva. A Internet, ou melhor, o acesso à web, se tornou uma obrigação, uma necessidade para todos os indivíduos que coabitam os ambientes sociais neste tempo. Essa tendência, ou um possivel deslocamento do real para o virtual pôde promover uma abreviação de distancias, mas também proporcionou novas formas de existência dos indivíduos. Sabe-se que a Internet $^{2}$ não é um fenômeno recente, remonta, no mínimo aos idos de 1940, onde existia enquanto uma ferramenta comunicativa de caráter militar, e secreto nos Estados Unidos.

Com o passar dos anos, e com acréscimo de complexidade de uma sociedade capitalista em latência, com suas reconfigurações econômicas e políticas - como paulatina supressão de uma sociedade de produtos de longa duração, a partir da década de 1960, para um modelo mais voltado ao consumo de bens não duráveis, também chamada de pósindustrial (BELL, 1974), na década de 1970, pôde-se observar que os computadores tiveram uma importante contribuição nesse chamado "turn" ou guinada tecnológica. Nesse sentido, houve uma transformação da ideia de realidade, na qual a existência (humana e social) caminhou para uma bifurcação que seria absorvida nas décadas seguintes, onde os computadores pessoais (PC's), de fato, conquistaram seu lugar.

\footnotetext{
2 Opto por grafar Internet com letra maiúscula, devido ao caráter de sujeito e por questões teóricas que ao longo do texto se farão presentes.
} 
Redes, sociedade informacional e internet: os usos políticos do on-line na contemporaneidade a partir da massificação de pós-verdade e fake news | Júlio Marinho Ferreira

Tendo em vista algumas das exposições acima, este trabalho busca fazer uma arqueologia dos conceitos que são fundamentais para o entendimento desta discussão acerca do impacto da tecnologia sobre os indivíduos, com isso, trago as origens do termo "rede", no âmbito da sociologia, de uma forma contextual, em seguida, trato de discutir o papel da informação e das mídias, na sociedade informacional, e como as mesmas criaram um novo ethos para o nascimento de uma quebra entre opinião pública e privada. Esses aspectos, somados, articulam às questões relativas à Internet e à interação on-line, além dos desdobramentos sociais, que podem ser (ou foram) nomeadas de sociedade panóptica, de controle, de exposição, e uma terminologia, uma polêmica, que surgiu nos últimos anos sociedade delirante (MOROZOV, 2019).

Ademais, procuro na informação - em sua origem - nas mídias em geral e na opinião pública -, em seus alcances próprios, que, articulados dentro de redes comunicacionais apontam para o fundamento de uma sociedade movida a opiniões, e à uma ruptura do público e do privado, em função da potencialidade de expor, vender (consumir) verdades. E com isso, esses três pontos também se apresentam como essenciais para o clareamento da exposição teórica aqui tentada: os problemas de um modelo social dependente de interação constante, que teriam nas redes sociais virtuais seu escape e sua potencialidade, que faz com que indivíduos troquem (vendem) dados por exposição.

Em suma, com este trabalho, e dentro de um escopo sociológico além de multidisciplinar, busco dar luz ao debate das potencialidades presentes nas redes sociais, sejam elas digitais ou virtuais, procurando apresentar uma outra perspectiva para certos debates sobre o tema, que parecem não contribuir sociologicamente sobre os debates dos impactos de uma sociedade cada vez mais imersa no on-line. Nesse sentido, procuro pontuar algumas questões acerca dos usos do on-line, e como a sociedade brasileira contemporânea, mas não apenas, parece impor uma digitalização da vida e uma inerente virtualização dos seres. 
Redes, sociedade informacional e internet: os usos políticos do on-line na contemporaneidade a partir da massificação de pós-verdade e fake news | Júlio Marinho Ferreira

\title{
Redes, informação, capitalismo e modernidade: antecessores de uma sociedade informacional
}

Como percebido há milênios pela filosofia aristotélica, e seus seguidores, o homem é um animal social, que precisa estar entre os seus para poder sentir sua existência, ser presença e vetor. Dentro dessas prerrogativas, o ato de falar, a comunicação, a necessidade de dialogar em prol de objetivos, e a interação - combinadas - fundem-se como o aspecto essencial da existência humano. Nesse sentido, a sociedade moderna pode ser entendida a partir do conceito de redes, já que as formações sociais, e seus mecanismos de coesão, requerem mecanismos que sirvam de cadeias, e que sejam formadores das mesmas, para que assim, a sociedade, em si, nasça como tal.

A terminologia rede, usada a todo momento e banalizada atualmente, tem sua origem há milênios, e paulatinamente teve seu significado mudado, e aderido, aos discursos sociais de cada época especifica. Na antiguidade, quando se falavam em redes, deveria se pensar na tecelagem, e no imaginário presente no labirinto, além da medicina de Hipócrates, que a associa à metáfora do organismo (MUSSO, 2010, pp. 17-18):

\begin{abstract}
Todavia, a palavra rede (réseau) só aparece na língua francesa no século XII, vindo do latim retiolus, diminutivo de retis, e do francês antigo résel: a rede designa, então, redes de caça ou pesca e tecidos, uma malhagem têxtil que envolve o corpo. Fios entrelaçados para os tecidos, os cordéis ou cestas, as malhas ou tecidos estão em torno do corpo. No século XVI, o termo réseaul significa, em francês antigo, os véus e rendas com que as mulheres cobriam a cabeça e, no século XVII, o pano que elas colocavam sobre suas camisas era um sutiã.
\end{abstract}

Rede, provém de inúmeros significados, e essa analogia com as rendas, foi cara a René Descartes (1596-1650), que a empregou em suas descrições sobre o cérebro humano, e o modo como os pensamentos fluíam e se conectavam, e isso, talvez seja a primeira analogia a potencialidade de conexão presente no termo. As redes, seriam para Descartes, uma ordem do físico, do corpo humano, estando presente em toda sua extensão.

Essa relação de exterioridade desaparece quando, a partir do século XVIII, o termo "rede", empregado pelos tecelões e cesteiros para qualificar a trama de fibras têxteis, passa a ser usado por médicos para designar e desenhar o aparelho sanguíneo e as fibras que compõem o corpo humano (MUSSO, 2010, p. 19). 
Redes, sociedade informacional e internet: os usos políticos do on-line na contemporaneidade a partir da massificação de pós-verdade e fake news | Júlio Marinho Ferreira

Usando o dicionário, temos a seguinte definição para rede como um tecido de malha com aberturas regulares e um entrelaçamento de fibras que são ligados por nós etc ${ }^{3}$,, essa terminologia se aproxima do que Descartes empregou, há séculos, como analogia ao funcionamento do cérebro humano. Ademais, cumpre deixar claro, que evocando o que anteriormente demarquei, o conceito e o significado de "rede" foram constantemente alterados por questões de caráter sócio-técnico, e com isso, hoje ao abrir-se um alfarrábio mais atual, tem-se já o termo "redes sociais" incluído nas nomenclaturas de rede:

\begin{abstract}
Hoje a noção de "rede é onipresente, e mesmo onipotente, em todas as disciplinas: nas ciências sociais, ela define sistemas de relações (redes sociais, de poder...) ou modos de organização (empresa-rede, por exemplo); na física, ela se identifica com análise dos cristais e dos sistemas desordenados (percolação); em matemática, informática, e inteligência artificial, ela define modelos de conexão (...)] (MUSSO, 2010, p. 17).
\end{abstract}

As redes sociais virtuais, então, o mote deste artigo, é um conceito que ainda precisa ser entendido em sua relação com os agentes, ou seja, os seus usuários, que apresentam particularidades nas formas de usufruir desses entrelaces do real/virtual e do digital/virtual através do uso de perfis on-line na web. Uma rede é uma possibilidade interativa aberta e fechada, ao mesmo tempo, o que a torna uma muitas vezes dificil de mensurar. "A polissemia da noção de rede explica seu sucesso, porém lança dúvida sobre a coerência do conceito" (MUSSO, p.17), já que se vislumbra algo em constante transformação.

Musso (2010), busca expor que a "rede é uma estrutura de interconexão instável, composta de elementos em interação, e cuja variabilidade obedece a alguma regra de funcionamento" (p. 31). Nesse sentido, ao pensar em redes, deve-se notar o alcance e seus niveis, o que Musso (2010), divide em três assertivas:

1- A rede é uma estrutura composta de elementos em interação, ligados entre si por caminhos ou ligações;

\footnotetext{
${ }^{3}$ Ver: https://www.dicio.com.br/rede/ Acesso em outubro de 2019.
} 
Redes, sociedade informacional e internet: os usos políticos do on-line na contemporaneidade a partir da massificação de pós-verdade e fake news | Júlio Marinho Ferreira

2- A rede é uma estrutura de interconexão instável no tempo;

3- As redes obedecem a regras de funcionamento (pp. 31-32).

A profundidade do ambiente virtual, que produz uma conexão em redes, como percebido por Musso, adquiriu uma importância quando fala-se em redes sociais na Internet, muitas vezes entendidas como formadoras de verdades, na qual a exposição de uma vida, pretendida ou idealizada, acabaria por quebrar a barreira entre o público e o privado, elemento importante nas formações sociais ao longo do tempo. Dessa quebra, ou ruptura com a realidade, nasceria uma dependência de uma vida on-line.

Um ponto importante para a análise do ambiente, e de sua dimensão de impacto pôde ser percebida na dualidade: esfera pública e esfera privada. Desses dois pontos, o sociólogo alemão Jürgen Habermas na obra "Mudança estrutural da esfera pública", trouxe uma marcante observação acerca da origem da palavra latina Opinio, da grega Doxa e da alemã Meinen, as três podendo ser traduzidas como opinião (2003). Com isso, através de sua conexão (fusão) com a noção de reputação, tem-se uma vida colocada para fora. Nesse sentido, opinar, seria demonstrar um juízo sem certeza, uma exposição infundada, em muitas (mas não sempre), já que esse opinar, precisa estar amparado por inúmeros aspectos, entre eles - e o principal - a dimensão da verdade.

A vida social fundida com a vida digital (NEGROPONTE, 1992), é o modo de viver (ser) da contemporaneidade, e o estar on-line - fruto de uma vivencia digitalizada, é estar em constante troca ou em reciprocidade. Dessa forma, uma vida em sociação, termo caro ao sociólogo, também alemão, Georg Simmel (1858-1918), pode ser percebida a partir da própria noção de sociedade, já que através de sua forma e conteúdo, surge a natureza do ser e sua busca por interação (Moraes Filho, 1983). Dessa forma, e de grupos, pode-se notar uma analogia a essa digitalização do mundo, deixando claro que, em Simmel, esse aspecto ainda não existia. No entanto, os aspectos interativos buscados seriam mito similares. 
Redes, sociedade informacional e internet: os usos políticos do on-line na contemporaneidade a partir da massificação de pós-verdade e fake news | Júlio Marinho Ferreira

Simmel (1983) apresenta essa sociação (do alemão, Vergellschaftung) como um processo constituído pelos impulsos dos individuos, ou por outros motivos, interesses e objetivos, isso somado às formas que essas ações tendem a assumir. No entanto, não basta a interação, é preciso que o indivíduo saiba que está agindo para e contra os outros (conflitos), dessa forma, não formaria uma unidade, e sim, uma sociedade. E o que mantém, e articula, essa sociedade são os grupos sociais, ademais, A informação, e sua capacidade de ser usada na formação de opiniões, ou de certezas infundadas (crenças), demonstra um vetor para a formação de certos agrupamentos e articulações.

Com isso, a informação, o ato de informar, é necessário entender os meios para a sua primazia:

\begin{abstract}
Os instrumentos modernos de enorme potência, desde a tipografia à fita do gravador sonoro e visual, por seu prestigio levaram quase à confusão com os meios propriamente ditos (a palavra sobretudo). Com isto fica obscurecida a visão do conjunto, porque a linguagem foi e continua sendo a raiz e o vincula da relação aos meios adquiriram hoje, sem dúvida, um reconhecimento excessivo, ou desproporcionado, de sua importância. O que há neles, e por trás deles. É o processo comunicativo mediante o qual se informa (BENEYTO, 1974, p. 09).
\end{abstract}

Juan Beneyto, teórico da informação, tratava de observar a relação entre o social e o informar, seguindo a toda de que não haveria sociedade sem informação, já que "seria uma necessidade psicológica e um ingrediente social (p. 09). Mas o que ele apontou, em décadas atrás, pode ser ainda percebido em quase todos os meios de comunicação nos dias de hoje, ou seja, a ascensão de um novo modelo de informar, a partir da reconfiguração do social a partir do modelo expressa pela tecnologia avançada.

De uma sociedade informativa para uma sociedade tecnológica reconfigurada pelos computadores - que passou a ser vista como uma sociedade voltada a informação, ou seja, informacional (LOJKINE, 1999; CASTELLS, 2003; 2005), que possibilitou uma abreviação das distâncias e uma maior relação de mercado global. Contudo, com o advento das novas formas de trabalho a partir da massificação dos computadores, um conhecimento mais técnico acabou por ser requerido (e não estaria acessivel 
Redes, sociedade informacional e internet: os usos políticos do on-line na contemporaneidade a partir da massificação de pós-verdade e fake news | Júlio Marinho Ferreira

a todos!). As relações sociais, naquela nova configuração, jamais seriam as mesmas, em todos os âmbitos, principalmente no mercado de trabalho.

A partir dos desdobramentos sociais, mencionados acima, como a informação, temos o surgimento de aparatos de vigilância, controle social e global - como satélites - que tem na informação seu meio de ação. A possibilidade de vermos sem sermos vistos, de saber o que se passa no mundo, em tempo real, sejam pelas câmeras em terminais de metrô ou outros aparatos, abriram caminho para uma lógica descentralizada de vigilância, algo mais próximo de uma distopia do que um modelo social.

A Internet, como a conhecemos hoje, é uma reconfiguração do modelo de redes interativas e informacionais, como demarcado por Manuel Castells (2003; 2005). Essa rede, reconfigurada, ou seja, a Internet, passou da chamada Web. 1.0 (anos 1990 ao início dos 2000), para a Web 2.0, em 2004 e por último, Web 3.0, em sua forma atual, sendo esse último modelo pautado pela possibilidade de plataformas interativas de maior capacidade de dados, de uma melhor portabilidade - a partir da massificação dos smartphones - e pela fácil manipulação das redes sociais virtuais que surgiram ${ }^{4}$.

Essas ferramentas ultramodernas e acessiveis a quase todos, no caso, os smartphones, dos nossos dias, são objetos que cabem nos bolsos e não saem das mãos dos indivíduos em quase todos os momentos do dia a dia. Em qualquer lugar que se anda nas cidades, e fora delas, sempre alguém o está usando ou simplesmente o carregando em seus bolsos. Isso fez surgir a questão do uso 24/7 (CRARY, 2014) ou uma lógica de consumo exacerbado de redes sociais virtuais, já que os smartphones são quase exclusivamente criadas para o uso dessas ferramentas interativas. Ademais, essa interação 24/7 diária, torna qualquer coisa um artigo que precisa ser exposto, e esse modelo de exposição seria o guia de todas as relações interativas pedidas (e perdidas) nas interfaces digitais/virtuais, na qual, a

\footnotetext{
4 Posso usar como exemplo o extinto Orkut, rede social norte americana lançada em 2004, tendo obtido sucesso principalmente em países populosos como Índia e Brasil. Deve seu nome ao engenheiro de computação do Google, o turco Orkut Büyükkökten. Essa rede social foi extinta em 2014 devido ao sucesso absoluto do Facebook, outra rede social.
} 
Redes, sociedade informacional e internet: os usos políticos do on-line na contemporaneidade a partir da massificação de pós-verdade e fake news | Júlio Marinho Ferreira

produção de dados se torna um meio de existir - ou uma virtualização dos seres emerge como fato.

A utilização das redes sociais virtuais (Facebook, Youtube, Instagram, etc.) como uma forma interativa, a possibilidade mais lembrada pelos usuários, fez com que várias esferas do social (independentes de classes e de renda) ${ }^{5}$ acabaram por ser impactadas por essas ideias de avanço, e nisso, as possibilidades democráticas de um ambiente comunicacional de caráter pessoal puderam ser talhadas na sequência, com isso, tem-se o ciberespaço como ambiente de ação e de práticas.

De um outro modo, não vai demorar muito para que empresas como o Facebook e a Alphabet recorram a um estratagema final e coloquem em risco a própria ideia de uma política democrática: vendendo a ideia de liberdade como o serviço digital supremo - que elas nos proporcionariam de bom grado, por uma pequena taxa, é claro (MOROZOV, 2019).

Yevgeny Morozov, é um jovem crítico de mídia e tecnologia, nascido na década de 1980, que através de artigos e de algumas obras expõe os problemas da chamada Big Tech ${ }^{6}$, não de forma pessimista, mas sim dando apontamento sobre os graves problemas do uso das redes nas esferas democráticas. Em sua obra mais recente lançada no Brasil, tem-se a questão das fake news e da utilização econômica da exposição via redes sociais como um mote crítico que pode ser usado por várias áreas do conhecimento. Morozov trouxe a dimensão dual da disruption, em que primeiro como elemento econômico pregaria escassez e alteridade, e segundo, com a tecnologia, que tornou tudo digitalizado e conectado, haveria uma celebração da abundância e da inovação (2019, p. 43).

A possibilidade de um espaço de ação, deslocada da realidade, teve na obra de ficção cientifica Neuromancer, de William Gibson, uma de suas

\footnotetext{
5 O Brasil é considerado o país da América do Sul que mais faz uso de redes sociais virtuais, principalmente pela massificação do uso de smartphones, que superam o número de habitantes. Em https://epocanegocios.globo.com/Tecnologia/noticia/2019/04/brasil-tem-230-milhoes-desmartphones-emuso.html\#targetText=Entre $\% 20$ os $\% 20$ aparelhos $\% 2 \mathrm{C} \% 20$ o $\% 20$ uso, ativos $\% 20 \mathrm{em} \% 20 \mathrm{rela} \% \mathrm{C} 3 \% \mathrm{~A} 7 \% \mathrm{C} 3$ \%A3o\%20a\%202018. Acesso em agosto de 2019.

${ }^{6}$ Big Four Tech Companies, GAFA, ou simplesmente Big Tech, refere-se às quatro grandes empresas de informática norte-americanas, Google, Amazon, Facebook e Apple, que monopolizaram as ações online na última década, dessa forma, liderando um exorbitante mercado e impondo padrões a ser seguidos.
} 
Redes, sociedade informacional e internet: os usos políticos do on-line na contemporaneidade a partir da massificação de pós-verdade e fake news | Júlio Marinho Ferreira

primeiras descrições. Esse ambiente interativo, nessa obra foi chamada de Matrix 7 . Esse livro foi lançado em 1984, bem no auge da revolução tecnológica promovida pelos computadores pessoais. Neuromancer, que depois acabou por ser descrita como uma criação literária cyberpunk ${ }^{8}$, revolucionou a forma de ver a Internet, principalmente em função de seus agentes, já que foi também uma das primeiras obras a descrever os chamados hackers 9 .

Para Morozov (2019), os hackers, com a digitalização do mundo (e da vida) se tornaram empreendedores e romperam as estruturas dos ambientes on-line, transformando o virtual em um mercado lucrativo. Além disso, esse mundo on-line, também chamado de ciberespaço é uma encarnação de um mundo "virtual", que nos confunde com sua dimensão ao mesmo tempo simbólica, técnica e social, e nos coloca frente a um novo território sem mapa, um espaço que pode ser público, cidadão e comercial (MUSSO, 2006).

\footnotetext{
No ciberespaço, cérebros e computadores estão, portanto, ligados entre si como já havia sonhado Wiener (1948), pois os dois dependem de uma mesma teoria unitária que dá conta de funcionamento das máquinas e dos organismos. Eles estão ao mesmo tempo decompostos em partes identificáveis (os chips eletrônicos equivalem aos neurônios) e "interconectados" para dar luz a uma pequena totalidade "inteligente" (o cérebro e o computador) e maleável a uma "grande totalidade" construída por analogia, a saber, o "cérebro planetário" (que liga cérebros e computadores interconectados), dotada de uma grande "inteligência coletiva" (MUSSO, 2006, p. 194).
}

O mundo virtual deve ser entendido a partir do conceito de Realidade Virtual (ou VR - virtual reality - no inglês), que comporta o chamado mundo 3D, a imersão, a simulação de realidade, ou a imaginação de uma realidade deslocada, que viria (ou nasceria) de uma ideia de mundo deslocado do real, no qual a tecnologia teria o papel central, isso, tendo como fonte a ficção cientifica (BELL, 2007).

O ciberespaço, desde sua ideia original presente na obra de Gibson, "Neuromancer" de 1984, seria um espaço desenvolvido artificialmente pela

\footnotetext{
7 Sendo a principal influência para o filme de mesmo nome, lançado em 1999.

8 Fusão dos termos: cibernética e punk, ou seja, demarcando a união entre o tecnológico (Cyber) e o comportamento crítico ao establishment (Punk), que trazem um tipo novo de indivíduo, criado pela sociedade informacional.

9 Deve-se pontuar que hacker não portaria o caráter negativo que esse termo carrega hoje em dia, um hacker, nos anos 1980 era um indivíduo que fazia uso dos ambientes on-line, com expertise e desenvoltura, criticando o capitalismo ao mesmo tempo que o usava. Os criminosos on-line são chamados de Crackers, ou seja, quebradores de códigos e senhas, invasores de perfis e contas que as vendem e chantageiam.
} 
Redes, sociedade informacional e internet: os usos políticos do on-line na contemporaneidade a partir da massificação de pós-verdade e fake news | Júlio Marinho Ferreira

convergência entre um mundo on-line gerado pelas redes telemáticas e as projeções digitais e imaginárias dos sujeitos, interagindo por seu intermédio (RÜDIGER, 2016). Partindo dessa ideia de um espaço artificial, na obra de Gibson, o cérebro funcionaria como um computador, e o computador funciona como um cérebro. Podemos perceber reflexos dessa ideia hoje em dia com as pesquisas em Inteligência Artificial (AI) em que são ensaiadas visões de futuro, além dos computadores e de suas "simples redes".

\section{Vidas digitais e seres virtuais: existe um homo panopticus?}

A complexidade da vida social nos últimos dois séculos se deve, principalmente, a inclusão de tecnologia de ponta nas esferas privadas, e de máquinas - anteriores geringonças dos ambientes insalubres de trabalho, nas fábricas do auge da Revolução Industrial para os atuais computadores de alta performance que cabem em mochilas e bolsos de roupas. Essa nova forma de interagir com as máquinas (ultra tecnológicas da atualidade), poderia ser fruto de uma noção de progresso, que acompanha a modernidade, incluindo essas mesmas máquinas na categoria de bens de consumos, agora acessiveis.

Rádio, aparelhos de reprodução de discos, televisão e os supracitados computadores são ferramentas interativas, antes de serem vistas como simples máquinas de um universo capitalistas. O que as fizeram especiais como mecanismos de alcance social foram suas capacidades de abreviar distâncias, e promover deslocamentos de realidades. Além disso, essas máquinas produziram bens a serem consumidos: informação (dados).

A mídia, que não é um fenômeno dos últimos dois séculos, se fortaleceu no século passado, alterando profundamente os indivíduos e sua relação com o mundo. Surgiram inúmeras potencialidades, principalmente acerca do consumo de si (noção de imagem). Essa mudança, se deve aos modos de viver na contemporaneidade, na qual o capitalismo, em seu estado avançado, proporcionou um melhor acesso ao mundo do consumo. Ademais, as duas grandes guerras (1914-1918 e 1939-1945), fizeram com que essa 
Redes, sociedade informacional e internet: os usos políticos do on-line na contemporaneidade a partir da massificação de pós-verdade e fake news | Júlio Marinho Ferreira

lógica de consumo fosse alterada, trazendo à baila a questão acerca do papel da tecnologia na vida dos indivíduos, alterando suas noções de trabalho, cultura, e até de realidade.

Além desse olhar sobre alguns pontos da ascensão da tecnologia na vida social, ao dar primazia ao termo virtual ao invés de digital, parte de uma noção pessoal (e crítica) sobre o papel do digital sobre o social, que parece ter pouco a pouco se imbricado na realidade social. Dessa forma, uma vida digitalizada é uma perspectiva particular, que uso como descrição do modelo atual de interação, que através de um estudo de certos pensadores (mais otimistas), como o anteriormente mencionado Nicholas Negroponte e sua obra “A vida digital”. Pensadores como Crary (2014), tem outras formas de perceber o digital:

A caracterização pseudo-histórica do presente como Era Digital, supostamente homologa a uma Idade do Bronze ou Era do Vapor, perpetua a ilusão de uma coesão unificadora e duradoura entre os inúmeros e incomensuráveis elementos constitutivos da experiência contemporânea (p.45).

Partindo de Crary (2014), que escreve nos dias atuais, e pegando um atalho ao passado, com Michel Foucault, filósofo francês, conhecido por suas profundas análises que versam sobre variados temas, na década de 1970, tem-se na emblemática obra "Vigiar e Punir" (1975; 2006) uma interessante análise de um momento da modernidade, que poderia ser usada como analogia para o modo como o mundo digital trata seus indivíduos (usuários). Nesse trabalho, Foucault (2006) buscou teorizar sobre o nascimento da prisão na modernidade, e não sobre o mundo digital, no entanto, emprego algumas de suas analises como forma de teorizar os usuários dos ambiente on-line, que nomeio de Homo Panopticus ${ }^{10}$.

Antes do advento das sociedades capitalistas modernas, os atos de vigiar e punir socialmente, eram prerrogativas do poder do soberano. Como o descrito por Foucault $(2006 ; 2010)$, a passagem do poder soberano para o

\footnotetext{
10 Homo panopticus, faz referência ao monstro mitológico Argos Panoptes que possuía mais de cem olhos em sua face, fato que o impossibilitaria de descansar, dessa forma estaria sempre olhando algo, sempre vigiando, sempre buscando. A analogia ao monstro mitológico pode ser encarada como ideal para uma sociedade que consome a vigilância e a exposição, desenvolvendo inúmeras ferramentas e dispositivos que tornem essas ações ainda mais refinadas, como as redes sociais on-line e os aplicativos de relacionamentos.
} 
Redes, sociedade informacional e internet: os usos políticos do on-line na contemporaneidade a partir da massificação de pós-verdade e fake news | Júlio Marinho Ferreira

poder disciplinar teve como simbolo o panóptico de Jeremy Bentham (17481832), jurista e filósofo político utilitarista britânico. O panóptico foi pensado e desenvolvido como projeto de recuperação de presos no final do século XVIII, em decorrência das transformações sociais e econômicas aceleradas que as revoluções industriais e urbanas geravam, o que se viu inicialmente à época foi uma sociedade mergulhada em um caos estrutural e social (Bentham, 2008). Dessa maneira, houve naquele momento uma preocupação com a recuperação social de indivíduos considerados desajustados.

A vigilância e a exposição promovidas pela Internet, com a adesão espontânea e não plenamente consciente ${ }^{11}$ (em muitos casos) dos usuários às implicações envolvidas, promove todo um aparato que coleta e organiza um conjunto de informações sobre aquilo que os indivíduos acessam nas sociais virtuais, e dessa forma, podem ser colocados como uma espécie de novo modelo de panóptico (HAN, 2018).

O filosofo sul-coreano Byung-Chul Han, analisa com lentes críticas o modo, e o impacto, das redes sociais nas relações entre indivíduos, e percebeu que a tecnologia, atrelada ao poder da informação, reconfigurou o modo de ser do indivíduo no social, e ao retomar o pensamento de Foucault, e a disciplina dos corpos:

O corpo como força produtiva não é mais tão central como na sociedade disciplinar biopolítica. Em vez de superar resistências corporais, processos psíquicos e mentais são otimizados para o aumento da produtividade. O disciplinamento corporal dá lugar a otimização mental. Assim, o neuro-enhancement ${ }^{12}$ se diferencia fundamentalmente das técnicas psiquiátricas disciplinares (HAN, 2018, p. 40).

Essa otimização, nada mais é que a lapidação constante de imagem virtual, que os usuários de redes sociais buscam a todo momento como forma de interação on-line constante. No entanto, ao recuar-se até a década de 1980, com a ideia de uma sociedade de controle, como percebida por

11 Como exemplo, surge a questão envolvendo os chamados algoritmos, que seriam tarefas, direcionamentos ou desvios desenvolvidos por ferramentas, em particular, produzindo "caminhos" para o consumo e para a exposição de dados. Ver: https://dicasdeprogramacao.com.br/o-que-ealgoritmo/

12 Aumento do rendimento psíquico a partir do uso de psicotrópicos. 
Redes, sociedade informacional e internet: os usos políticos do on-line na contemporaneidade a partir da massificação de pós-verdade e fake news | Júlio Marinho Ferreira

Gilles Deleuze (1992), tem-se no capitalismo, e sua capacidade de produzir endividamento nos indivíduos, uma forma de captura. E essa captura, talvez seja fruto de certas etapas da sociedade moderna, que busco problematizar nos desdobramentos dos modelos:

a) Panóptica, como descrita por Jeremy Bentham (2008), e melhor teorizado por Foucault (2006);

b) Controle, como demarcada por Deleuze (1992), Crary (2014);

c) Exposição a partir da tecnologia virtual atuando nos indivíduos, Han (2018);

d) Delirante (MOROZOV, 2019).

O digital não dá mais conta da natureza politica, econômica, e até mística da Internet, percebida não mais como uma rede interativa, e sim como um ente, um ser a guiar a humanidade, e esse jeito de ver o virtual tenderia a promover um ambiente deslocado do real, e delirante (Morozov, 2019).

Esse homo panopticus, que tento esboçar como um reflexo de uma sociedade que usa as redes sociais dentro de uma lógica 24/7 (CRARY, 2014), que fundiria a digitalização da vida e a virtualização do ser, seria fruto da fusão das noções de panopticismo (docilidade dos corpos), de controle (economia), de exposição (perda da cisão público/privado) e do último, analogamente descrito por Morozov (2019), que seria delirante e extremamente problemático, já que gera mentiras e irrealidades que acabariam por ser aceitas e assimilados como reais.

Porém, como pontuou Crary (2014):

24/7 é um tempo de indiferença, contra qual a fragilidade da vida humana é cada vez maia inadequada, e dentro do qual o sono não é necessário nem inevitável. Em relação ao trabalho, torna plausivel, até normal, a ideia de trabalhar sem pausa, sem limites. Alinha-se com o inanimado, com o inerte ou com o que não envelhece (CRARY, 2014, p. 19).

Ainda para Crary (2014), a Internet enquanto uma ferramenta de um capitalismo tardio, e da rapidez do progresso, tendeu a acelerar a vida cotidiana, levando os indivíduos a perder da noção do tempo, no qual os segundos teriam mais importância que os minutos. Tudo deve ser o mais rápido possivel, tudo deve ser instantâneo, principalmente o trabalho e o 
Redes, sociedade informacional e internet: os usos políticos do on-line na contemporaneidade a partir da massificação de pós-verdade e fake news | Júlio Marinho Ferreira

sono. Dormir parece ser uma perda de tempo, e estar on-line deveria ser 24/7 ou 24/365-6, já que novidades surgem a todo instante?

“Um mundo 24/7 é desencantado, sem sombras nem obscuridade ou temporalidades alternativas. É um mundo idêntico a si mesmo, um mundo com o mais superficial dos passados, e por isso sem espectros" (p.29). Crary (2014), a todo momento busca entender como a realidade humana acabou tão alterada pela tecnologia, e como seria proceder (ou viver) com esse novo real (virtual?).

A realidade, dessa forma, parece afetada pela virtualidade, e reconfigurada a partir de um deslocamento e de uma quebra (temporal), que levou a uma absorção do real pelo virtual. Aos usuários de redes sociais virtuais, essa ação parecer uma benesse, já que no mundo virtual a imagem de si poderia ser manipulada, e reconfigurada, de todas as formas possiveis. Ser o que sempre se quis parece a chave da interação deslocada.

No entanto, cumpre distinguir o real do virtual:

a) Real ou realidade, provém da terminologia latina, realitas, ou seja, uma coisa. Coisa essa, que pode ser vista, sentida, mensurada etc. O real é um conceito estudada por várias áreas do conhecimento, sendo na filosofia objeto de debates há décadas, como na obra de Martin Heidegger (1889-1976) e Gilles Deleuze (1925-1995);

b) Virtual ou virtualidade, em Deleuze, se refere ao aspecto do real encarado como ideal, ou seja, a representação idealizada de uma imagem existente ou não. Dessa forma, ainda em Deleuze, o virtual teria dois aspectos: um efeito produzido a partir da interação com a materialidade, e uma potencialidade preenchida com ações, sendo real, ainda que não material.

As potencialidades por detrás da informação, e da imagem em sua forma estética, enquanto representação sensível de uma coisa, pode se valer presente neste dualismo entre o real e o virtual, que adquire valores abstratos e concretos. E dependendo dos seus usos, transformaria em realidades a mentira e o delírio, e verdade seria apenas uma crença para 
Redes, sociedade informacional e internet: os usos políticos do on-line na contemporaneidade a partir da massificação de pós-verdade e fake news | Júlio Marinho Ferreira

aqueles que não teriam um conhecimento especifico do que se trataria a informação, imagem ou vídeos. Quando se fala em informação, tem-se que deixar claro que se tratam de dados, que são vendidos e comprados, e não verdades.

Os dados são o novo petróleo (MOROZOV, 2018), pode-se pensar, ou os dados são o novo ardil para os incautos? E isso fica claro ao se notar que a privacidade é custosa e nada atraente em um modelo social de exposição, que prega o acesso ao virtual como uma forma de viver e ser feliz! Para francês Baudrillard, um ferrenho crítico da sociedade de consumo, a tecnologia impactou a vida social, seja na cultura, na economia ou na arte, produzindo dessa forma um mundo virtual, artificial, fazendo com que uma dormência e uma apatia se apoderasse dos individuos (BAUDRILLARD, 1991).

Em suma, essa virtualidade, como uma potência, adviria de uma capacidade de criação de ambientes/territórios, presente no dualismo espírito/corpo e real/virtual, que parece não querer ser assimilado pelos indivíduos (usuários de redes sociais) como uma dualidade (que fragmenta ao invés de unir e aproximar).

\section{A pós-verdade como produto de uma sociedade delirante: fakes, Catfishes, fake news e o nascimento de um cibereleitorado}

Os rumos que a sociedade brasileira tomou nos últimos cinco anos, de onde este trabalho se fundou, podem ser percebidos a partir de uma análise da relação do brasileiro com as interfaces on-line. Nunca se usou tanto a Internet como agora, e isso trouxe novas formas de existência. A possibilidade de existência on-line não demanda o existir em seu sentido real, e sim um ente simulado, já que imitaria algum processo existente na vida real (Baudrillard, 1991). E dessa ação, sempre poderia surgir algo que seja visto como verdade.

Verdade significa algo que tenha conformidade com o objeto e com a realidade, mas a superação do significado do que seria a verdade, é uma relação constante nos ambientes on-line, e isso acabou sendo descrito como 
Redes, sociedade informacional e internet: os usos políticos do on-line na contemporaneidade a partir da massificação de pós-verdade e fake news | Júlio Marinho Ferreira

uma pós-verdade ${ }^{13}$. Uma pós-verdade diz respeito a manipulação da opinião pública, sendo um neologismo muito empregado na atualidade, principalmente a partir de seus usos políticos (D’Ancona, 2018). Ao se usar essas pós-verdades, um indivíduo busca articular crenças, emoções e sentimentos profundos que estão presentes no dia a dia dos seres humanos, em suas vidas e conversas rotineiras.

Como percebido por Schudson (2004), existem principios que envolvem o ato de conversar, e com isso:

\begin{abstract}
Reconhecer a tensão entre os princípios da conversação é uma forma de chagar a uma visão mais coerente e realista da mesma. Eu proponho, de forma alternativa, que dois diferentes ideais da conversação sejam entrelaçados e confusos. Um ideal e o outro como modelo que resolveproblemas (SCHUDSON, 2004, p. 64).
\end{abstract}

Uma pós-verdade não significa automaticamente uma mentira, e sim os seus usos a partir de uma informação, sendo que essa informação poderia ser verdadeira. O envolvimento de crenças pessoais, e sua manipulação por parte de indivíduos (na maioria das vezes políticos) é o que a torna problemática para a democracia e o livre pensar. Como Schudson (2004) percebeu, "o problema central para a democracia moderna é a face do desenvolvimento nos métodos e condições de debate, discussão e persuasão" (p.65). Um debate que seja respeitoso, parece ter sido afastado dos ambientes on-line, e uma das hipóteses cogitadas para essa fuga, seja a nova forma de percepção temporal, onde o tempo parece fluir mais rápido e a necessidade de responder (e acreditar) teria que ser mais rápida ainda.

O FOMO (Fear of Missing Out, no original em inglês), é um termo norte-americano criado como uma crítica a nova noção de tempo no ciberespaço, onde tudo tenderia a ser visto, compartilhado e comentado com pressa. Ou seja, ao sentirmos o constante medo de perder algo, estaríamos sempre à mercê de enganadores e de mecanismos tendenciosos. O teórico Jonathan Crary, que via nisso uma das novas lógicas da sociedade

\footnotetext{
13 Deve-se pontuar que a pós-verdade se difere das chamadas fake news (notícias falsas), por mais que sejam muitas vezes confundidas. Uma pós-verdade envolve o uso de apelativos emocionais, já as notícias falsas (fake news) nada mais seriam que criações voltadas a enganar. Ver: https://www.significados.com.br/pos-verdade/. Acesso em outubro de 2019.
} 
Redes, sociedade informacional e internet: os usos políticos do on-line na contemporaneidade a partir da massificação de pós-verdade e fake news | Júlio Marinho Ferreira

informacional, na qual a noção de tempo convencional é alterada por uma necessidade de um tempo mais rápido. Dessa forma, tudo deveria ser visto, comentado e compartilhado da forma mais rápida possivel.

Opinião pessoal tornada real, nada mais seria que a utilização da crença como verdade, não importando seus resultados. Para o sociólogo canadense Erving Goffman, o embaraço, um dos aspectos mais marcantes e mais distintos dos seres humanos, como percebido por Charles Darwin - é uma forma (ação) que sempre deveria ser evitada, havendo inúmeros mecanismos para isso, um deles, sendo a mentira e o ato de propagar essa mentira e ficar falando a todo momento sobre o assunto (fraudulento). Ainda, segundo Goffman:

Falar é um exemplo do que um acordo onde indivíduos ficam juntos e suportam problemas tendo uma confirmação, uma articulação, uma corrente e exigindo atenção, exigências as quais os colocam juntos sob uma certa forma de mundo mental intersubjetivos (GOFFMAN, 1981, pp. 70-71).

Os usos políticos da mentira, do boato e dessas pós-verdades, podem ser melhor mensurados na nova relação política da sociedade com as interfaces informacionais, e de seus usos on-line. Esse eleitor imerso no ciberespaço, tem no Brasil, país que conta com um número maior de smartphones do que habitantes ${ }^{14}$, uma forma de experimentar o real, e tendo na Internet, na web e nas redes sociais virtuais sua forma de expressão, e de vivencias. Essas interações em redes sociais, que são amplamente usadas, por todos os cibereleitores promoveram latências, que na relação entre uma vida exposta constantemente, na falência do privado em detrimento ao público, uma interação paradoxal em suas vidas. Como percebido por Michel Maffesoli: "Uma sociedade não tem mais consciência do que a une e, a partir de então, não tem mais confiança nos valores que asseguram a solidez do vínculo social" (2010, p. 13).

O cibereleitor parece que perdeu o contato com a realidade, ou parece não mais se importar com o real, sua vida seria apenas social no

14https://www.em.com.br/app/noticia/economia/2019/04/26/internas_economia, 1049125/brasiltem-230-mi-de-smartphones-em-uso.shtml 
Redes, sociedade informacional e internet: os usos políticos do on-line na contemporaneidade a partir da massificação de pós-verdade e fake news | Júlio Marinho Ferreira

ciberespaço. Essa forma de existir, afetaria sua noção de sociedade, e dessa forma, seu eu social precisaria ser resgatado:

Talvez seja isso que chamamos, sem muita consciência, de societal. Não é mais o simples social dominado pelo racional, tendo por expressão o político e o econômico, mas outra maneira de estar-junto, em que o imaginário, o onírico, o lúdico, justamente, ocupam um lugar primordial (MAFFESOLI, 2010, p. 26)

A relação de confiança que a politica deveria passar, sua percepção e a sua capacidade de formar laços de confiança, estariam ausentes e fragmentados por caracteres problemáticos como os boatos e a pós-verdade, já que os valores sociais de uma democracia não são mais percebidos e sentidos dentro desse contexto. A reputação, importante medidor on-line, se torna uma busca importante, e sua constante manipulação, dentro da lógica 24/7 (Crary, 2014) se reconfigura como o legitimador de ações e verdades. A reputação nas redes sociais virtuais seria ser aceito e seguido, quanto mais seguidores mais aceitação, e mais aceitação daria mais legitimidade.

Nos perfis on-line, de redes sociais como Facebook, Youtube, Twitter e Instagram ${ }^{15}$, o uso dos chamados avatares ${ }^{16}$ é uma prática comum e difundida. No entanto, uma questão problemática se mostra nos usos dessas contas, que são usadas não mais como imagens limitadas ao ciberespaço e sim como seres reais. Dessa forma, nessas redes sociais virtuais, o uso de perfis falsos se tornou algo corriqueiro, podendo ser divididos em perfis de variados tipos, e formar imagens e potencialidades, conforme suas ações e motivações:

a) Os Fakes são as contas/perfis falsos presentes em todas as redes sociais virtuais, nesse sentido, podendo ser de caráter pessoal, político, empresarial, sexual, etc. Esses perfis são extremamente comuns. ${ }^{17}$ Ademais, por sua natureza não condizente com a

\footnotetext{
15 Citando novamente as redes sociais mais usadas no Brasil.

16 É um corpo, ou ente criado no mundo on-line, ou seja, um corpo digital.

17 Segundo o site Social Catfish, que recebe denúncias e procura investigar essas práticas, o número de perfis fakes somam cerca de $15 \%$ das contas nas principais redes sociais virtuais. Ver: https://socialcatfish.com/blog/where-do-fake-social-media-profiles-come-

from/?utm_source=Blog + and + Footer + Signup\&utm_campaign=c8505892ff-

Fake_Social_Media_Infographic\&utm_medium=emailoutm_term=0_51cbf6253f-c8505892ff-

111283157 Acesso em outubro de 2019.
} 
Redes, sociedade informacional e internet: os usos políticos do on-line na contemporaneidade a partir da massificação de pós-verdade e fake news | Júlio Marinho Ferreira

realidade fica dificil mensurar sua intencionalidade e suas origens, já que a Internet enquanto uma interface global impossibilitaria certos tipos de rastreio;

b) Os Catfishes ${ }^{18}$ são perfis que visam apenas enganar outros perfis, isso através do uso de conteúdos extraídos de outras contas (que não as suas), como imagens, vídeos e fotos pessoais. O conteúdo de um perfil desse tipo geralmente busca uma legitimação pela aparência, pela demonstração de um estilo de vida sexy e elitizado, onde imperam uma forte acentuação dos padrões sociais relativos à beleza e bem-estar. Ou seja, um perfil Catfish geralmente faz uso da imagem de alguém bonito, dentro de um padrão social de beleza, como forma de atração e agenciamento de desejos.

Estudos mostram que nessas principais redes sociais, os números de perfis não-reais são alarmantes, no caso do Facebook, a principal e mais usada rede social do mundo, são contabilizados mais 80 milhões de contas falsas $^{19}$. Nas eleições norte-americanas de 2016, o então candidato, Donald Trump foi acusado de fazer uso de artificios fraudulentos via redes sociais virtuais, isso com a ajuda de crackers de origem russa. Foram atribuidos o uso de milhares de contas falsas a seu favor, o que entanto, não ficou totalmente provado, e ainda está em julgamento.

Para autores como Weissberg (WEISSBERG, 2011), o virtual seria uma dimensão diversa do real, porém, não se opondo a ela, uma vez que, torna-se parte constitutiva do que hoje se entende por realidade. Dessa forma, o objeto virtual, no caso aqui pesquisado, mais especificamente os perfis em redes sociais virtuais e as imagens neles contidas apresentam-se como manifestações que compõem este espaço virtual da realidade vivenciada daquelas pessoas que cada vez mais vivem conectadas.

$\mathrm{O}$ ato de deslocar uma vida para o mundo on-line, ou criar uma nova vida para isso (os fakes) seriam manifestações de um tipo indivíduo (que

\footnotetext{
18 Termo oriundo de um documentário norte-americano, de mesmo nome, lançado em 2010, que descreve a busca de um indivíduo que foi agenciado no Facebook por um falso usuário. Em 2012, acabou transformado em programa da MTV dos EUA. 19 Ver: https://tecnoblog.net/108742/facebook-perfis-falsos /
} 
Redes, sociedade informacional e internet: os usos políticos do on-line na contemporaneidade a partir da massificação de pós-verdade e fake news | Júlio Marinho Ferreira

precisa ou requer uma vivência virtual), e uma dependência dessa mesma vida - não como perfis agenciadores - como no caso dos Catfishes, que seria de outro tipo. No entanto, ambas experiências (vivências) estariam amparadas pelo mundo virtual:

O virtual no lugar do real corresponde a uma dicotomia visivelmente exportada das categorias da representação, como por exemplo, imagem no lugar do objeto, máquinas no lugar do homem etc. (WEISSBERG, 2011, p. 119).

A refiguração (representação de uma imagem nas interfaces virtuais) dos indivíduos a partir do uso e do controle de sua autoimagem, seja através de perfis fakes, Catfishes ou não, pôde promover uma aproximação nunca antes vista entre os politicos e seus eleitores, que aqui chamo de cibereleitorado. Dessa forma, o cibereleitor surgiu como um individuo de um mundo altamente informatizado, que teria no ciberespaço das redes sociais virtuais uma extensão de sua vivência. Ser representado, ou querer ser representado, fundindo-se com o mundo real, promovendo uma necessidade de ser on-line como existir realmente.

Já dentro da afirmação do cibereleitorado, tem-se as fake news, que nos últimos três anos dominaram o cenário jornalístico e político, acabaram por ser coringas a ser usados, principalmente por Trump e Bolsonaro, como forma de deslegitimar tudo o que fosse contra suas propostas, "sob a ótica das plataformas digitais, as fake news são apenas as notícias mais lucrativas" (MOROZOV, 2019). Com isso, empresas de marketing, especialistas em propagar notícias falsas, boatos se estabeleceram e fizeram amplo uso dessas possibilidades, principalmente via WhatsApp.

Em suma, os usos das redes sociais, seja por indivíduos comuns ou por candidatos precisam ser vistas de uma maneira mais crítica, tendo em relevo as potencialidades que uma sociedade de exposição acabou legando a um contexto no qual a Internet dominou há pelo menos 20 anos. Nesse sentido, ao trazer um olhar sociológico, e parcialmente político, sobre o fenômeno do novo eleitor - ou cibereleitorado como aqui chamado - foi 
Redes, sociedade informacional e internet: os usos políticos do on-line na contemporaneidade a partir da massificação de pós-verdade e fake news | Júlio Marinho Ferreira

necessário a utilização de categorias analíticas abrangentes, por se tratar de uma terminologia nova.

\section{Considerações finais}

Este artigo procurou versar sobre algumas relações oriundas do consumo acrítico de uma ideia de existência on-line, que afetou a percepção da realidade - a interação em redes sociais virtuais, que alterando o modo de percepção entre o real e o virtual. Essas percepções - ou potencialidades seriam produtos de uma sociedade que teria na exposição sua forma de interação. E essa interação só teria efeito nas interfaces virtuais (redes sociais). Nesse sentido, o Brasil, enquanto país que consome o on-line massivamente, se torna um importante medidor das relações que as interfaces virtuais promoveram aos seres humanos.

Ao buscar as origens da opinião pública e sua relação com a sociedade tecnológica avançada, que situo a partir da década de 1950, momento no qual, os computadores - a partir do surgimento dos microprocessadores tornarem primais na produção e no trabalho - articulo com a necessidade humana de comunicação (de falar), que acabaria por ser usada, e manipulada, se tornando pós-verdades e utilizadas por indivíduos mal-intencionados. Ao apresentar alguns desses indivíduos, sejam eles: fakes, Catfishes, propagadores de notícias falsas, como políticos e usuários on-line, busquei apresentar, brevemente, suas potencialidades, além de seu público cativo, que chamo de cibereleitorado.

A relação buscada, neste trabalho, foi articular conceitos sociológicos com uma literatura mais vasta, já que o digital/virtual, ainda seria pouco analisado pela sociologia, enquanto disciplina e uma multidisciplinaridade em muitos momentos se fez necessária. Com isso, procurei lançar mão de alguns neologismos e criações próprias, como no caso do homo panopticus, que podem ser usadas como modelo explicativo para as interações nas interfaces virtuais, e com isso, potencializar o debate que tentei propor, ou seja, encarar as redes sociais de uma maneira crítica e perceber que a mesma produziria um consumo acrítico de muitos aspectos problemáticos 
Redes, sociedade informacional e internet: os usos políticos do on-line na contemporaneidade a partir da massificação de pós-verdade e fake news | Júlio Marinho Ferreira

do social, além dos seus usos fraudulentos que geram ainda mais uma digitalização da vida e uma virtualização dos seres. 
Redes, sociedade informacional e internet: os usos políticos do on-line na contemporaneidade a partir da massificação de pós-verdade e fake news | Júlio Marinho Ferreira

\section{Referências}

BAUDRILLARD, Jean. Simulacros e Simulação. Lisboa: Relógio D’água, 1991.

BELL, Daniel. O advento da sociedade pós-industrial. São Paulo: Cultrix, 1974

BELL, David. Cyberculture Theorists. Manuel Castells and Donna Haraway. New York: Routledge, 2007.

BENTHAM, Jeremy. O Panóptico. Belo Horizonte/MG: Editora Autêntica, 2008.

CASTELLS. Manuel. A galáxia da Internet: reflexões sobre a internet, os negócios e a sociedade. Rio de Janeiro: Jorge Zahar Editor, 2003.

CASTELLS, Manuel. A sociedade em rede. A era da informação: economia, sociedade e cultura. Volume 1. São Paulo: Paz e Terra, 2005.

CRARY, Jonathan. 24/7. Capitalismo e os fins do sono. São Paulo: Cosac Naify, 2014. COSTA, Rogério da. Sociedade de Controle. São Paulo em Perspectiva, 18(1): 161-167, 2004.

D'ANCONA, Matthew. Pós-Verdade. A nova guerra contra os fatos em tempos de Fake News. Barueri: Faro Editorial, 2018.

DELEUZE, Gilles. Post-Scriptum sobre a sociedade de controle. IN: Conversações 1970-1992. São Paulo: Ed. 34, 1992, pp. 219-226.

DESCARTES, René. O discurso do método. São Paulo: Martins Fontes, 1996.

FOUCAULT, Michel. Em defesa da Sociedade. São Paulo: Martins Fontes, 2010. FOUCAULT, Michel. Vigiar e Punir: O nascimento da prisão. Petrópolis/RJ: Vozes, 2006.

GIBSON, William. Neuromancer. São Paulo: Aleph, 2016.

GOFFMAN, Erving. Forms of Talk. Philadelphia: University of Pennsylvania, 1981. HABERMAS, Jürgen. Mudança estrutural da esfera pública. Investigações quanto a uma categoria da sociedade burguesa. Rio de Janeiro: Tempo Brasileiro, 2003.

HAN, Byung-Chul. Psicopolitica - O neoliberalismo e as novas técnicas de poder. Belo Horizonte/Veneza: Editora Âyiné, 2018.

LOJKINE, Jean. A Revolução Informacional. São Paulo: Cortez, 1999. 
Redes, sociedade informacional e internet: os usos políticos do on-line na contemporaneidade a partir da massificação de pós-verdade e fake news | Júlio Marinho Ferreira

MAFFESOLI, Michel. Apocalipse. Opinião pública e opinião publicada. Porto Alegre: Sulina, 2010.

MOROZOV, Yevgeny. Big Tech. A ascensão dos dados e a morte da politica. São Paulo: Editora Ubu, 2019.

MUSSO, Pierre. Ciberespaço, figura reticular da utopia tecnológica. IN: MORAES, Dênis de. Sociedade Midiatizada. Rio de Janeiro: Mauad, 2006.

MUSSO, Pierre. A filosofia da rede. IN: PARENTE, André. As Tramas da Rede. Novas dimensões filosóficas, estéticas e politicas da comunicação. Porto Alegre: Sulina, 2010.

NEGROPONTE, Nicholas. A Vida Digital. São Paulo: Companhia das Letras, 1992.

PARENTE, André. As Tramas da Rede. Novas dimensões filosóficas, estéticas e politicas da comunicação. Porto Alegre: Sulina, 2010.

RÜDIGER, Francisco. As teorias da Cibercultura. Perspectivas, questões e autores. Porto Alegre: Sulina, 2016.

SCHUDSON, Michael. Porque a conversação não é a alma da democracia? IN: MARTINS, Francisco M. e DA SILVA, Juremir M. A genealogia do virtual: comunicação, cultura e tecnologias do imaginário. Porto Alegre: Sulina, 2004.

SIMMEL, Georg. MORAES FILHO, E. Sociologia. São Paulo: Ática, 1983.

WEISSBERG. Jean-Louis. Real e Virtual. IN: PARENTE, André (org.) Imagem-Máquina. Rio de Janeiro: Editora 34, 2011. pp.117-127.

WIENER, Norbert. Cibernética e Sociedade. São Paulo: Cultrix, 1976. 